\title{
FAKTOR PREDIKTOR TERJADINYA DEPRESI POSTPARTUM DI RUMAH SAKIT PANTI RAPIH YOGYAKARTA
}

\author{
Agnes Mahayanti ${ }^{1}$, Intansari Nurjannah ${ }^{2}$, Widyawati $^{3}$ \\ ${ }^{1}$ STIKes Panti Rapih Yogyakarta, mahayanti.agnes@gmail.com \\ ${ }^{2}$ Universitas Gadjah Mada, intansari@ugm.ac.id \\ ${ }^{3}$ Universitas Gadjah Mada, widyawati.poernomo@ugm.ac.id
}

\begin{abstract}
ABSTRAK
Latar Belakang: Periode postpartum merupakan proses adaptasi fisik dan psikologis. Bentuk gangguan psikologis yang dapat muncul adalah postpartum blues, depresi postpartum, dan psikosis postpartum.

Tujuan: Penelitian ini bertujuan untuk mengetahui kejadian depresi postpartum, mengidentifikasi faktor prediktor terjadinya depresi postpartum dan mengidentifikasi faktor prediktor dominan terjadinya depresi postpartum.

Metode: Penelitian menggunakan desain cross sectional. Sampel adalah ibu hamil yang dipilih dengan teknik random sampling. Pengumpulan data untuk mengukur faktor prediktor terjadinya depresi postpartum dilakukan dengan kuesioner Revision Postpartum Depression Predictors Inventory (PDPI) dan untuk mengukur skor depresi digunakan dengan Edinburgh Postnatal Depression Scale (EPDS). Analisa data dilakukan dengan univariat, bivariat dengan uji statistik chi-square tes serta multivariat dengan uji regresi logistik.

Hasil: Hasil penelitian menunjukkan bahwa faktor prediktor yang signifikan adalahstatus ekonomi, harga diri, kepuasan dalam perkawinan, postpartumblues, dan depresi prenatal. Faktor prediktor dominan adalah kepuasan dalam perkawinan dengan nilai $t 2,778$ kali.

Simpulan: Hasil penelitian menunjukkan bahwa kepuasan dalam perkawinan merupakan faktor prediktor dominan terjadinya depresi postpartum, ini menunjukkan bahwa kepuasan dalam perkawinan atau kualitas hubungan dengan pasangan merupakan salah satu support sistem yang penting oleh karena perlu adanya keterlibatan pasangan dalam tindakan-tindakan perawatan selama periode kehamilan sampai dengan masa nifas sebagai upaya-upaya pencegahan terjadinya depresi postpartum.
\end{abstract}

Kata kunci: depresi postpartum, periode postpartum, postpartum bues 


\begin{abstract}
Background: The postpartum period was a physical and psychological adaptation process. Psychological disturbances could present in form of postpartum blues, postpartum depression, and postpartum psychosis.

Objective: The objective of this research was to determine the incidence of postpartum depression, identify predictors of postpartum depression and identify the dominant predictors of postpartum depression.

Methods: this research used a cross sectional design. Sample were pregnant women which were chosen by random sampling technique. Data was collected with questionnaire to measure the predictors of postpartum depression was carried out with the Revision Postpartum Depression Predictors Inventory (PDPI) questionnaire and to measure depression scores used with the Edinburgh Postnatal Depression Scale (EPDS). Data analysis was done by univariate and bivariate analysis with with chi-square statistical tests and multivariate with logistic regression tests.

Results: The results showed that the significant predictors were economic status, self-esteem, marital satisfaction, postpartum blues, and prenatal depression. The dominant predictor factor is satisfaction in marriage with a $t$ value of 2.778 times.

Conclusion: The results of the study show that marital satisfaction is a dominant predictor of postpartum depression, indicating that marital satisfaction or relationship quality is one of the important support systems because of the need for partner involvement in care actions during the pregnancy period until with the puerperium as efforts to prevent postpartum depression.
\end{abstract}

Keywords: postpartum depression, postpartum period, postpartum bues

\title{
PENDAHULUAN
}

Kesehatan merupakan hak
dasar manusia yang menentukan
kualitas sumber daya manusia
(SDM). Hal ini menjadi alasan
pentingnya peningkatan kualitas
kesehatan. Menurut Laporan
Kesehatan Ibu Anak (KIA) tahun
2018 angka kematian ibu (AKI)
masih berkisar 305 per kelahiran

hidup. Komplikasi utama yang menyebabkan $80 \%$ dari semua kematian ibu adalah: perdarahan hebat, infeksi, pre-eklampsia, dan eklampsia dan aborsi yang tidak aman. (Sumber: Key facts. Maternal Mortality. 16 February 2018 https://www.who.int/ news- 
room/fact sheets/detail/maternalmortality).

Sebagian besar kematian
maternal terjadi pada trimester
ketiga kehamilan, persalinan, dan
minggu pertama setelah melahirkan.
Kehamilan, persalinan, dan
postpartum memerlukan proses
adaptasi fisik dan psikologis. Bentuk gangguan psikologis yang dapat muncul adalah 1) Postpartum blues, muncul dalam minggu pertama postpartum dengan prevalensi sebesar 30-75\% dan akan segera hilang (Allasoom et al., 2014; Ray et.al., 2015). Gejala yang muncul berupa reaksi depresi/sedih/disforia, menangis, mudah tersinggung (iritabilitas), cemas, labilitas perasaan, cenderung menyalahkan diri sendiri, gangguan tidur, dan gangguan nafsu makan (Savage, 1875 cit. Bowles et al., 2005). 2) Depresi Postpartum adalah gangguan mood yang secara historis sering diabaikan dalam perawatan kesehatan dengan membiarkan ibu menderita dalam ketakutan, kebingungan, dan keheningan. Jika hal ini tidak terdiagnosa, dapat mempengaruhi hubungan ibu-bayi dan menyebabkan masalah emosional jangka panjang bagi anak (Bowles et al., 2005; McGrath et al., 2008). Prevalensi 10-15\% 3) Psikosis postpartum yang umumnya terjadi pada minggu ke-4 pertama setelah melahirkan. Prevalensi psikosis postpartum adalah sekitar 1-2 per 1000 kelahiran.

Menurut hasil penelitian Putriarsih (2018) yang dilakukan pada 200 orang ibu postpartum di pusat kesehatan masyarakat di Kabupaten Sukoharjo Jawa Tengah didapatkan hasil 18,5\% ibu mengalami depresi postpartum. Penelitian terkait kejadian depresi postpartum juga dilakukan oleh Tikmani (2016) pada 46 ibu postpartum di Rumah Sakit Tersier Karachi dimana prevalensi depresi postpartum adalah 22,3\%. Berdasarkan penelitian Rismintari (2012) yang dilakukan pada $192 \mathrm{ibu}$ postpartum di bangsal kebidanan Rumah Sakit Umum Pusat DR. Sardjito Yogyakarta ditemukan bahwa prevalensi depresi postpartum adalah $11,3 \%$ untuk depresi ringan, $1,9 \%$ untuk depresi sedang dan $0,5 \%$ untuk depresi berat. 
Faktor Prediktor Terjadinya Depresi Postpartum di Rumah Sakit Panti Rapih Yogyakarta

Peran perawat dan keterlibatan profesi kesehatan secara profesional sangat diperlukan untuk melakukan deteksi dini dan pencegahan depresi postpartum. Kesiapan psikologis ibu dan keluarga perlu diperhatikan sejak masa kehamilan. Pada ibu hamil, menjadi cemas atau tertekan selama kehamilan membawa prognosis yang buruk untuk penyesuaian setelah melahirkan, oleh karena itu sangat penting untuk melakukan skrining faktor prediktor terjadinya depresi postpartum pada ibu hamil untuk tiap semesternya. Menurut Beck (2002) depresi selama kehamilan merupakan salah satu prediktor terkuat terjadinya depresi postpartum yang dapat terjadi selama kehamilan.

\section{Beberapa alat/instrumen}

telah dirancang dan dikembangkan untuk mengidentifikasi ibu yang berisiko tinggi terjadi depresi postpartum. Alat/instrumen yang digunakan adalah Revision of the Postpartum Depression Predictors Inventory yang berisi tentang 13 prediktor terjadinya depresi postpartum. Cheklist ini digunakan pada tiap trimester kehamilan dan dilanjutkan pada saat ibu sudah melahirkan untuk memantau perubahan faktor resiko yang ada.

Berdasarkan hasil studi pendahuluan yang dilakukan di Rumah Sakit Panti Rapih Yogyakarta dalam bulan JuliSeptember 2014 menunjukkan bahwa jumlah data kunjungan Antenatal Care (ANC) adalah sebanyak 1206 pasien dengan ratarata dalam 1 bulan 402 pasien dengan rincian $50,08 \%$ primigravida dan 49,91\% multigravida. Sebesar $29,6 \%$ dari data ini merupakan kehamilan yang disertai dengan komplikasi/penyulit kehamilan seperti abortus, kehamilan disertai dengan penyakit kronis (Diabetes Miletus, Anemia, Hipertensi, Asma), kehamilan gemmeli, Hemorrhage Antepartum (HAP), hyperemesis gravidarum (Rekam Medis Rumah Sakit Panti Rapih Yogyakarta).

Penelitian tentang depresi postpartum di Rumah Sakit Panti Rapih belum pernah dilakukan sehingga peneliti tertarik untuk melakukan penelitian tentang faktor prediktor terjadinya depresi postpartum. 


\section{METODE PENELITIAN}

$$
\text { Jenis penelitian yang }
$$

digunakan adalah penelitian analitik dengan desain penelitian cross secsional. Penelitian dilakukan di Rumah Sakit Panti Rapih Yogyakarta pada bulan Juni-Agustus 2015. Jumlah responden adalah sebanyak 34 responden. Kriteria responden dalam penelitian ini adalah ibu hamil dengan usia kehamilan $\geq 36$ minggu, primigravida atau multigravida dengan jumlah anak $\geq 3$. Alat yang digunakan dalam penelitian ini berupa kuesioner Revision Postpartum Depression Predictors Inventory (PDPI) yang digunakan untuk mengukur faktor prediktor terjadinya depresi postpartum. Untuk mengukur skor depresi digunakan dengan Edinburgh Postnatal Depression Scale (EPDS) yang terdiri dari 10 pertanyaan dengan skor maksimum 30 dengan cutoff point 10. Pengambilan data dilakukan pada minggu I postpartum dengan EPDS dan PDPI. Analisa data dilakukan dengan univariat, bivariat dengan uji statistik chi-

square test dan multivariat dengan menggunakan uji regresi logistik.

\section{HASIL DAN PEMBAHASAN}

Hasil analisis karakteristik responden yang terdiri dari usia, pendidikan, jenis pekerjaan, paritas, dan status perkawinan dapat dilihat pada tabel berikut:

\section{Tabel 1}

Distribusi Frekuensi Karkteristik Responden di Rumah Sakit Panti Rapih Yogyakarta Bulan Juni-Agustus 2015

\begin{tabular}{|l|c|c|}
\hline KARAKTERISTIK & $\mathrm{n}=34$ & $\%$ \\
\hline Usia & & \\
\hline$<20 \&>35$ tahun & 1 & 2,9 \\
\hline $20-35$ tahun & 33 & 97,1 \\
\hline Paritas & & \\
\hline Primigravida & 24 & 70.6 \\
\hline Multigravida & 10 & 29.4 \\
\hline Pendidikan & & \\
\hline SMP & 0 & 0 \\
\hline SMA & 6 & 17,6 \\
\hline Perguruan Tinggi & 28 & 82,4 \\
\hline Pekerjaan & & \\
\hline Tidak Bekerja & 15 & 44,1 \\
\hline Bekerja & 19 & 55,9 \\
\hline Status Perkawinan & & \\
\hline Tidak Menikah & 1 & 2,9 \\
\hline Menikah & 33 & 97,1 \\
\hline Total & 34 & 100 \\
\hline
\end{tabular}


Faktor Prediktor Terjadinya Depresi Postpartum di Rumah Sakit Panti Rapih Yogyakarta

Tabel 2

Distribusi Frekuensi Responden Berdasarkan Skor EPDS dan Kejadian Depresi di Rumah Sakit Panti Rapih Yogyakarta Bulan JuniAgustus 2015

\begin{tabular}{|l|c|c|}
\hline \multicolumn{1}{|c|}{$\begin{array}{c}\text { KEJADIAN } \\
\text { DEPRESI }\end{array}$} & $\mathrm{n}=34$ & \\
\hline Skor EPDS & & \\
\hline Mean (Min-Maks) & $7,62(1-18)$ & \\
\hline Tidak depresi & 5 & 14,7 \\
\hline Rentan Depresi & 19 & 55,9 \\
\hline Depresi & 10 & 29,4 \\
\hline Skor PDPI & & \\
\hline Risiko rendah & 20 & 58,82 \\
\hline Risiko sedang & 11 & 32,3 \\
\hline Risiko tinggi & 3 & 8,82 \\
\hline Total & $\mathbf{3 4}$ & $\mathbf{1 0 0}$ \\
\hline
\end{tabular}

Tabel 2 menunjukkan bahwa angka kejadian depresi pada minggu I postpartum 29,4\%. Berdasarkan skor EPDS, persentase terbesar pada responden yang mengalami rentan terjadinya depresi $(55,9 \%)$ dengan skor EPDS rata-rata 7,62. Berdasarkan skor PDPI, persentase terbesar adalah risiko rendah $(58,82 \%)$.
Tabel 3

Distribusi Faktor Prediktor dengan Kejadian Depresi Postpartum pada Kelompok Intervensi dan Kontrol di Rumah Sakit Panti Rapih

Yogyakarta Bulan Juni-Agustus 2015

\begin{tabular}{|l|c|c|}
\hline FAKTOR PREDIKTOR & $p$-value & $\mathrm{r}$ \\
\hline Perkawinan & 0,43 & .217 \\
\hline Status Ekonomi & 0,62 & 089 \\
\hline Harga Diri & $\mathbf{0 , 0 1}$ & $\mathbf{. 4 2 6}$ \\
\hline Depresi Prenatal & 0,31 & .254 \\
\hline Ansietas Prenatal & 0,08 & .356 \\
\hline Dukungan Sosial & 0,73 & .135 \\
\hline $\begin{array}{l}\text { Kehamilan yang Tidak } \\
\text { Diinginkan }\end{array}$ & 0,07 & .363 \\
\hline $\begin{array}{l}\text { Kepuasan dalam } \\
\text { perkawinan }\end{array}$ & $\mathbf{0 , 0 0}$ & $\mathbf{. 4 7 2}$ \\
\hline Stres Hidup & 0,50 & .197 \\
\hline Stres Perawatan Anak & 0,34 & .243 \\
\hline Temperamen Bayi & 0,73 & .134 \\
\hline Postpartum Blues & $\mathbf{0 , 0 2}$ & $\mathbf{. 4 2 5}$ \\
\hline
\end{tabular}

Berdasarkan tabel 3 dapat diketahui faktor prediktor yang terdiri dari harga diri, kepuasan dalam perkawinan dan postpartum blues memiliki hubungan bermakna $(p<0.05)$ terhadap terjadinya depresi postpartum.

Tabel 4

Faktor Dominan Terjadinya Depresi Postpartum Pada Kelompok Intervensi dan Kelompok Kontrol di Rumah Sakit Panti Rapih Yogyakarta Bulan JuniAgustus 2015

\begin{tabular}{|l|c|c|}
\hline & $P$-value & Nilai t \\
\hline Harga Diri & 0,17 & 1,404 \\
\hline $\begin{array}{l}\text { Kepuasan dalam } \\
\text { perkawinan }\end{array}$ & $\mathbf{0 , 0 1}$ & $\mathbf{2 . 7 7 8}$ \\
\hline Postpartum blues & 0,09 & 1.728 \\
\hline
\end{tabular}


Faktor prediktor dominan yang mampu memicu terjadinya depresi postpartum adalah kepuasan dalam perkawinan yang berpotensi meningkatkan kejadian depresi postpartum 2,778 kali lipat daripada orang yang tidak mengalami kepuasan dalam perkawinan (tabel 4).

\section{PEMBAHASAN}

Penyebab pasti dari depresi postpartum tidak diketahui, namun banyak faktor prediktor yang diduga berperan terhadap terjadinya depresi postpartum. Faktor prediktor kepuasan dalam perkawinan teridentifikasi sebagai prediktor dominan terjadinya depresi postpartum. Hal ini tidak sesuai dengan hasil penelitian Beck (2002) dan Alasom dan Kaura (2014) yang menyatakan bahwa faktor dominan adalah depresi prenatal dan riwayat depresi, namun penelitian ini senada dengan penelitian Tikmani (2016) dan Putriarsih (2018) yang menyatakan bahwa tidak ada dukungan keluarga merupakan penentu independen dari depresi postpartum, di mana salah satu bentuk dukungan dari keluarga adalah kualitas hubungan yang baik suami istri yang berdampak pada kepuasan dalam perkawinan. Hal ini menunjukkan tidak ada faktor prediktor yang konsisten dari satu penelitian dibandingkan dengan penelitian lain. Faktor prediktor yang ditemukan adalah status ekonomi, harga diri, kepuasan dalam perkawinan postpartumblues dan depresi prenatal, menurut penulis kemungkinan dapat disebabkan karena 1) terdapat 3 faktor prediktor yaitu temperamen bayi, stres perawatan anak dan postpartumblues pada saat periode kehamilan belum bisa diukur, dan baru bisa dilakukan pengukuran setelah responden melahirkan. 2) Adanya perubahan hormonal yang fluktuatif sejak dari masa kehamilan sampai dengan kelahiran, seperti yang dijelaskan Beck (1999) dan Stone dan Menken (2008) bahwa selama kehamilan kadar hormon estrogen, progesteron, Corticotropin Releasing Hormon (CRH) meningkat drastis dan akan berkurang drastis pada hari kelima 
Faktor Prediktor Terjadinya Depresi Postpartum di Rumah Sakit Panti Rapih Yogyakarta

postpartum. Diduga peningkatan dan penurunan secara drastis tersebut dapat menyebabkan sensitifitas yang berbeda pada wanita pada saat kehamilan dan persalinan (Gondo,2011). 3) Adanya proses transisi peran melalui 4 tahap anticipatory, formal, informal dan personal. Ibu dengan depresi postpartum terjadi karena ketidakberhasilan dalam melewati proses transisi peran tersebut (Nazara, 2009)4) Adanya proses adaptasi psikologis pada periode postpartum dari fase taking in, taking hold dan letting go yang berbeda tiap individu. Menurut Mercer cit Alligood dan Tomey (2006) permasalahan psikologis dapat muncul pada fase taking hold dimana ibu sudah mulai berfokus pada bayinya namun sering muncul kekhawatiran, kurang percaya diri dan kecemasan pada ibu dalam melakukan perawatan bayinya. Kelainan psikologis ini dapat membaik atau bertambah parah. Hanya saja penelitian ini tidak meneliti sejauh mana faktor hormonal, adaptasi psikologis dan proses transisi peran ini berperan pada terjadinya depresi postpartum pada responden.

Peran perawat/bidan sangat diperlukan dalam proses transisi peran dan adaptasi psikologis karena ibu membutuhkan dukungan untuk belajar dan pendidikan kesehatan sangat efektif diberikan untuk membantu ibu mencapai peran barunya sehingga ibu meyakinkan dirinya mempunyai kompetensi sebagai seorang ibu. Perubahan konsep keperawatan maternitas dari pendekatan tradisional ke pendekatan yang berpusat pada keluarga (FamilyCenter Care) juga dapat membantu penanganan masalah depresi postpartum. Keterlibatan suami dan anggota keluarga lainnya sangat diperlukan dan perawat/bidan berperan memfasilitasi keterlibatan seluruh anggota dalam membantu keluarga agar mampu membuat keputusan untuk perawatan mereka.

Untuk meminimalkan angka kejadian depresi postpartum adalah melakukan deteksi dini/identifikasi awal wanita yang beresiko tinggi terjadinya depresi postpartum karena identifikasi secara dini dan inisiasi 
pendekatan terapi yang tepat waktu baik yang berupa strategi farmakologis maupun pendekatan psikoterapi merupakan faktor kunci untuk keberhasilan pengelolaan depresi postpartum (Ray et al., 2015).

Di Rumah Sakit Panti Rapih sudah ada program kegiatan pendidikan kesehatan yang dilakukan untuk memberikan informasi tentang kehamilan, persalinan serta perawatan setelah melahirkan oleh karena itu tindakantindakan tersebut dapat dilakukan untuk mempersiapkan ibu hamil sehingga tidak mengalami masalah psikologis pada saat periode postpartum.

\section{KESIMPULAN DAN SARAN}

\section{Kesimpulan}

Angka kejadian depresi pada minggu I postpartum 29,4\%. Berdasarkan skor EPDS persentase terbesar pada responden yang mengalami rentan terjadinya depresi
$55,9 \%$. Faktor prediktor yang memiliki hubungan signifikan terhadap terjadinya depresi postpartum adalah harga diri, kepuasan dalam perkawinan, dan postpartum blues. Faktor prediktor dominan yang mampu memicu terjadinya depresi postpartum adalah kepuasan dalam perkawinan yang berpotensi meningkatkan kejadian depresi postpartum 2,778 kali lipat daripada orang yang tidak mengalami kepuasan dalam perkawinan.

\section{Saran}

Bagi tenaga kesehatan (perawat/bidan) yang bertugas di Poliklinik Kebidanan Rumah Sakit Panti Rapih perlu melakukan skrining faktor prediktor terjadinya depresi postpartum pada saat ibu hamil melakukan pemeriksaan Antenatal Care (ANC) untuk mengetahui apakah ada faktor psikososial yang dapat menyebabkan terjadinya depresi postpartum. 
Faktor Prediktor Terjadinya Depresi Postpartum di Rumah Sakit Panti Rapih Yogyakarta

\section{DAFTAR PUSTAKA}

Alligood, R.M., dan Tomey, M.R., 2006, Nursing Theory Utilization and Aplplication, 3rd ed. Mosby Elsevier, U.S.A.

Allipour, Z., Lamyian, M., Hajizadeh, E., 2012, Anxiety and Fear of Childbirth as Predictors of Postnatal Depression in Nulliparaous Women, 25 (3), 37-43.

Badan Pusat Statistik, 2012, Survey Demografi dan Kesehatan Indonesia, Kemenkes RI.

Beck, C.T., 1999, Maternal Depression and Child Behaviour Problems: A Meta Analysis, J. Adv. Nurs., 29, 623-629.

Beck, C.T., 2002, Revision of the Postpartum Depression Predictors Inventory, JOGNN, 31 (4), 394-402.

Bowles, B., Coleman, N., dan Jansen, L., 2005, Postpartum Depression: Education and Early Detection, J. Obstet. Gynecol. Nurs., 1-28.

Cox, J.L., Holden, J.M., dan Sagovsky, R., 1987, Detection of Postnatal Depression: Developments of the 10-item Edinburgh Postnatal Depression Scale, British Journal of Psychiatry 150, 782-786.
Dahlan, S.M., 2013, Statistik Untuk Kedokteran dan Kesehatan: Deskripsi,Bivariat dan Multivariat, dilengkapi Aplikasi dengan menggunakan SPSS, Edisi ke5. Salemba Medika, Jakarta.

Depkes., 2011, Upaya Percepatan Penurunan Angka Kematian Ibu, Direktorat Bina Kesehatan Ibu Jakarta (internet), $<$ http://www.kesehatanibu.de pkes.go.id $>$ (diakses tanggal 5 Februari 2015).

Jardri, R., Pelta, J., Maron, M., Thomas, P., Delion, P., Codaccioni, $\mathrm{X}$., dan Goudemand, M., 2006, Predictive Validation Study Of The Edinburgh Postnatal Depression Scale in The First Week After Delivery And Risk Analysis for Postnatal Depression, J. Affect. Disord. 93, 169-176.

Gondo, H.K., 2011, Skrining Edinburgh Postnatal Depression Scale (EPDS) pada Postpartum Blues. Bagian Obstet. Dan Ginekol. Fak. Kedokt. Univ. Wijaya Kusuma Surabaya.

Kurniasari D, Astuti YA (2015). Hubungan antara karakteristik ibu, kondisi bayi dan dukungan sosial suami dengan postpartum blues pada ibu dengan persalinan SC di Rumah Sakit Umum Ahmd 
Yani Metro Tahun 2014. Jurnal Kesehatan Holistik, 9(3): 115-125.

Lee, L.C., dan Hung, C. H., 2015, Predictors of Postpartum Stress in Vietnamese Immigrant Women in Taiwan, Jpn J Nurs Sci, 2.

Nazara, Y., 2009, Efektivitas Intervensi Psikoedukasi Terhadap Pencegahan Depresi Postpartum di Kabupaten Nias, Maj Obstet Ginekol Indones, Vol 33 (4), 216-223.

Notoatmodjo, S., 2012, Metodologi penelitian kesehatan, Rineka Cipta, Jakarta.

Nugroho, I.P.S., 2008, Hubungan Dukungan Keluarga dengan Kejadian Depresi Postpartum pada Ibu Pasca Melahirkan di Puskesmas Tegalrejo Yogyakarta, Skripsi: Program Studi Ilmu Keperawatan Fakultas Kedokteran Universitas Gadjah Mada Yogyakarta.
Putriarsih.et.al. (2018). Prevalence and Determinants of Postpartum Depression in Sukoharjo District, Central Java. Journal of Maternal and Child Health, 3(1): 395-408.

Ray, S., Pathak, A., dan Sharma,I., 2015, Postpartum Psychiaric Disorder: Early Diagnosis and Management. Indian $J$ Psychiatry 57, S216-S221.

Tikmani, Shiyam, Soomro, Tufail., dan Tikmani Prashant, 2016, Prevalence and Determinants of Postpartum Depression in a Tertiary Care Hospital. Austin Journal of Obstetrics and Gynecology July 15, 2016. 